\title{
Phosphodiesterase (PDE)-4 Inhibitors and COPD Correlation with Cancer
}

\author{
John Organtzis ${ }^{1}$, Sofia Lampaki ${ }^{1}$, Paul Zarogoulidis ${ }^{1}$, Haidong Huang², Qiang Li $^{2}$, Antonis \\ Papaiwannou ${ }^{1}$, Konstantinos Syrigos ${ }^{3}$, Konstantinos Porpodis ${ }^{1}$, Theodora Tsiouda ${ }^{4}$, Wolfgang \\ Hohenforst-Schmidt ${ }^{5}$, Georgia Trakada ${ }^{6}$, Robert Fred Henry Walter ${ }^{7,8}$, Dimitra Makrantonaki ${ }^{9}$, Georgia \\ Pitsiou1, Ioannis Kioumis ${ }^{1}$, Konstantinos Zarogoulidis ${ }^{1}$ \\ 1. Pulmonary Department-Oncology Unit, “'G. Papanikolaou“ General Hospital, Aristotle University of Thessaloniki, Thessaloniki, Greece \\ 2. Department of Respiratory Diseases Shanghai Hospital, II Military University Hospital, Shanghai, China \\ 3. Oncology Department, “'Sotiria“" Hospital of Chest Diseases, University of Athens, Athens, Greece \\ 4. Internal Medicine Department, “Thegeneio“" Cancer Hospital, Thessaloniki, Greece \\ 5. II Medical Department, "Coburg“" Regional Clinic, University of Wuerzburg, Coburg, Germany \\ 6. Department of Clinical Therapeutics, Division of Pneumonology, Medical School, National University of Athens, Athens, Greece \\ 7. Ruhrlandklinik, West German Cancer Center, University Hospital Essen, University of Duisburg-Essen, Essen, Germany \\ 8. Institute of Pathology, University Hospital Essen, University of Duisburg-Essen, Essen, Germany \\ 9. Internal Medicine Department, "Theagenio“"Anti-Cancer Hospital, Thessaloniki, Greece.
}

$\square$ Corresponding author: Paul Zarogoulidis, Pulmonary Department, “'G. Papanikolaou“ General Hospital, Aristotle University of Thessaloniki. Thessaloniki, Greece. Fax: 00302130992433 Tel: 00302310340370 Email: pzarog@hotmail.com.

(c) Ivyspring International Publisher. This is an open-access article distributed under the terms of the Creative Commons License (http://creativecommons.org/ licenses/by-nc-nd/3.0/). Reproduction is permitted for personal, noncommercial use, provided that the article is in whole, unmodified, and properly cited.

Received: 2014.05.25; Accepted: 2014.07.02; Published: 2014.08.01

\begin{abstract}
A new drug for chronic obstructive pulmonary disease has been recently added as a treatment for certain patients. However, new evidences indicate that there might be a connection with lung cancer. It is known that smoking is a major factor that induces chronic pulmonary disease and smoking is associated with lung cancer. The level of connection between phosphodiesterase (PDE)-4 inhibitors and lung cancer will be discussed based on current studies. A comment will be made whether lung cancer is induced to patients receiving phosphodiesterase (PDE)-4 inhibitors from the drug or former smoking habit.
\end{abstract}

Key words: COPD, phosphodiesterase, inflammation, cancer.

\section{Introduction}

Chronic obstructive pulmonary disease (COPD) is the fourth most common cause of death in the US and is also a major cause of morbidity.[1] Lung parenchymal destruction, e/g. emphysema, and obstructive bronchiolitis are the typical patho-logic changes in COPD and are characterized functionally by progressive airway obstruction. Inflammatory changes and Mucus gland hyperplasia in the larger airways may also occur, and are accompanied by chronic cough and mucus hypersecretion.[2] The clinical course of COPD is punctuated by exacerbations, periods of deterioration characterized by worsening dyspnea, and increases in cough, sputum volume, and Sputum purulence usually associated with respiratory tract infection. Acute exacerbations of COPD are accompanied by acute deterioration in lung function and worsening disability. More frequent exacerbations are associated with a more rapid decline in lung function. [3] Exacerbations that are severe enough to require hospitalization are particularly ominous because they are associated with significant in-hospital mortality, and discharged patients have a $9 \%$ mortality rate within 30 days, and $28 \%$ are dead within one year. CD68 macrophages and CD8 Tlymphocytes are the predominant inflammatory cells in COPD, with polymorphs increasing during acute exacerbations. The severity of inflammation in the small airways and lung parenchyma increases with 
worsening COPD. These alterations contribute to airways thickening, resulting in luminal narrowing, and parenchymal destruction diminishes elastic recoil. Along with mucus hypersecretion, these abnormalities contribute to airways obstruction and to the reduction in airflow. In COPD, blood levels of the pro-inflammatory cytokines interleukin (IL)-1B, IL-6, and tumor necrosis factor-a (TNF-a) are increased. The level of IL=32, a recently described cytokine expressed in bronchial epithelium, macrophages, and CD8 cells which promotes TNF-a, IL-8, and CXCL2 expression, is also elevated and correlates with the reductions in forced expiratory volume in one second (FEV1) in COPD patients.[4] COPD is associated with a variety of comorbidities and extrapulmonary symptoms. It has been suggested that the association between COPD and these other conditions is due to the inflammatory process extending systemically. Leukocyte counts and blood levels of C-reactive protein, fibrinogen, and TNFa are higher in COPD patients compared with matched controls.[5] Systemic inflammation is associated with, and appears to be a risk factor for, a variety of symptoms and conditions including weight loss, muscle wasting, atherosclerosis, malignancy, osteoporosis, diabetes, and anemia. One novel class of compounds that may deliver therapeutic Benefit in COPD is phosphodiesterase (PDE)-4 inhibitors. PDE is a generic term that describes a large superfamily of Enzymes that catalyze the breakdown of cyclic adenosine 3,5-monophosphate-cGMP to their respective inactive nucleotide 5-monophosphates.[6] Eleven distinct PDE families have been identified, although most of the anti-inflammatory activity is believed to result from the inhibition of PDE 4, for which there is clinical precedent. Roflumilast is synthesized in five steps from 3-cyclopropylmethoxy-4-hydroxybenzaldehyde. [7] Figure 1, 2. The rationale for developing selective PDE4 inhibitors is based on three critical findings: PDE4 regulates camp degradation in most immume and pro-inflammatory Cells; in cell-based systems, PDE4 inhibitors of varied structural classes suppress a plethora of responses that are considered to be proinflammatory; and PDE4 inhibitors are efficacious in preclinical animal models that attempt to reproduce specific facets of COPD pathobiology.[8]

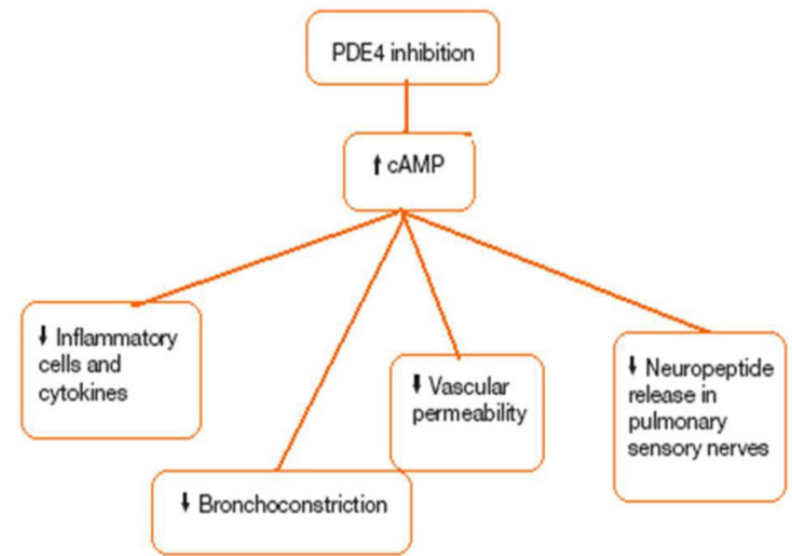

Figure I. PDE4; Phosphodiesterase 4, cAMP; Cyclic adenosine monophosphate.

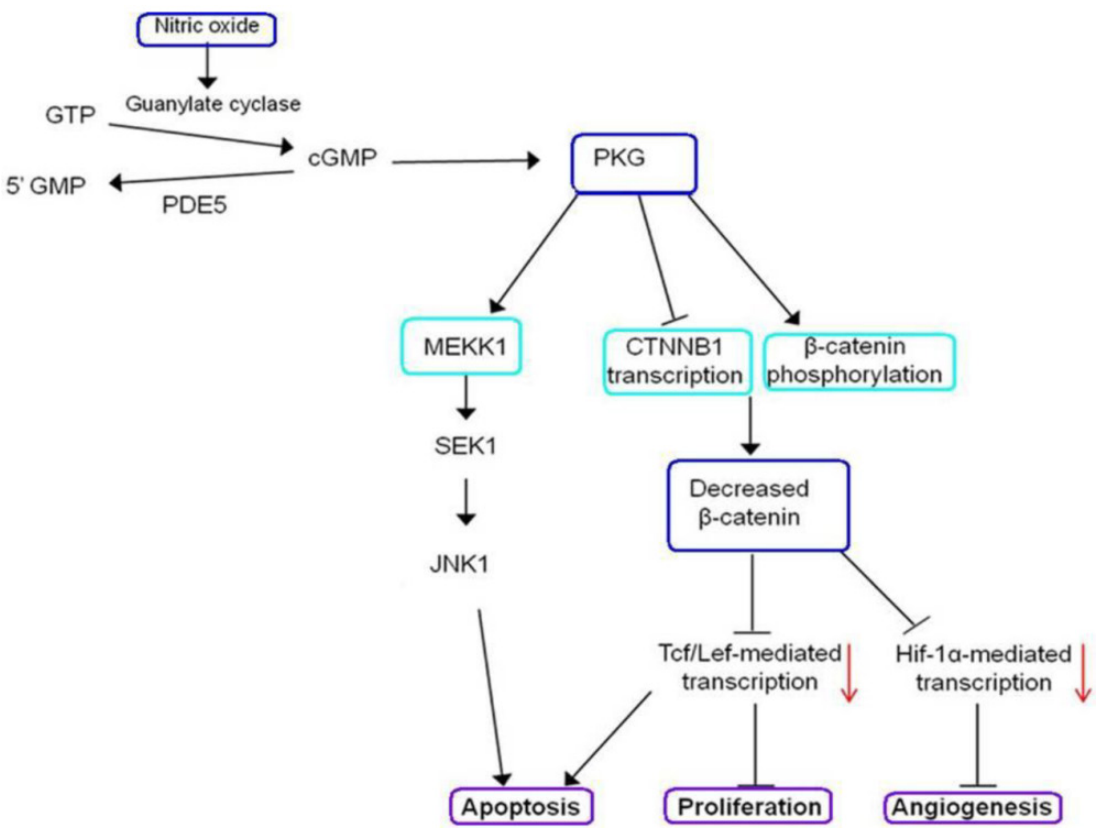

Figure 2. GTP; Guanosine-5'-triphosphate, cGMP; cyclic guanosine monophosphate, MEKK I; a protein kinase of the STEII family, CTNNB I; Catenin, beta-I, JNK I; c-Jun N-terminal protein kinase, PKG; cGMP-dependent protein kinase or Protein Kinase G, PDE5; A phosphodiesterase type 5 inhibitor, Tcf/Lef; T cell factor/lymphoid enhancer factor, Hif-I $\alpha$; Hypoxia-inducible factor I-alpha, SEKI; SAPK/ERK kinase-I. 
There are major differences between several and the FDA analysts' reports with respect to the number and severity of roflumilast side-effects. $[9,10]$ The analyst reports showed more intractable diarrhea, acute pancreatitis, weight loss, and psychiatric symptoms, and significantly more prostate, lung, and colorectal cancers in the roflumilast groups compared with the placebo groups. In the four studies analyzed by FDA staff, intractable diarrhea needing hospital admission was seen in five patients on the drug and in none on placebo. There were four cases of acute pancreatitis in the roflumilast group and one in the placebo group. Weight loss was carefully measured in the M2-124 and M-125 studies. The FDA reviews show that, in the roflumilast group, $67,4 \%$ had weight loss compared with $37,7 \%$ In the placebo group. Severe weight loss, defined as loss of more than $10 \%$ of bodyweights, was seen in $7,1 \%$ versus $1,9 \%$ in the roflumilast and placebo groups, respectively.[11] Weight loss was greatest in the patients with most severe COPD who were least able to tolerate it. The average weight loss of patients in the roflumilast groups was About $2,5 \mathrm{~kg}$. However, loss of $10 \%$ of bodyweight in 1 year in $7 \%$ of cases is a serious problem over a lifetime of roflumilast use. The FDA analysts' reports combine data from several studies when reporting the incidence of cancer. The incidence of cancers was significantly higher in the roflumilast group than the placebo group. Studies in animals also showed an increase in cancer on roflumilast. Even though these observations do not establish a cause and effect relation, it is a side-effect that cannot be ignored. Analysis of the overall roflumilast clinical development program revealed a total of 218 cancers/tumors in 208 patients. Disproportionately more $\{\mathrm{n}=131,60 \%\}$ of these lesions were in the roflumilast-treatment group when compared with placebo. Specifically, there was a greater Incidence of lung and prostate cancer reported in patients given roflumilast than those individuals given placebo. The significance of this observation is unclear. If roflumilast is carcinogenic, one might expect a greater than one-year latency period before tumors develop. Indeed, people smoke cigarettes for decades before they get lung cancer. Thus, the possibility that these findings are a chance observation, similar to the initial reports with omalizumab, rather than a response to treatment, should not be dismissed. Long-term studies were conducted in hamsters and mice with roflumilast to evaluate its carcinogenic potential. In 2-years oral gavage carcinogenetic studies, roflumilast treatment resulted in dose-related, statistically significant increases in the incidence of undifferentiated carcinomas of nasal epithelium in hamsters at $>8 \mathrm{mg} / \mathrm{kg} /$ day [approximately 11 times the MRHD based on summed AUCs of roflumilast and its metabolites]. Supplementary Table 1.

The tumorigenicity of roflumilast appears to be attributed to a reactive metabolite of 4-amino-3,5dichloropyridine $\mathrm{N}$-oxide [ADCP N-oxide]. No evidence to tumor-genicity was observed in mice at roflumilast oral doses up to 12 and $18 \mathrm{mg} / \mathrm{kg}$ / day in females and males, respectively [approximately 10 and 15 times the MRHD, respectively, based on summed AUCs of roflumilast and its metabolites].

\section{Supplementary Material}

Supplementary Table 1. Published studies. http://www.jcancer.org/v05p0625s1.pdf

\section{Competing Interests}

The authors have declared that no competing interest exists.

\section{References}

1. Rabe KF, Hurd S, Anzueto A, Barnes PJ, Buist SA, Calverley P, et al. Global strategy for the diagnosis, management, and prevention of chronic obstructive pulmonary disease: GOLD executive summary. Am J Respir Crit Care Med. 2007; 176: 532-55. doi:200703-456SO [pii]10.1164/rccm.200703-456SO.

2. Angelis N, Porpodis K, Zarogoulidis P, Spyratos D, Kioumis I, Papaiwannou A, et al. Airway inflammation in chronic obstructive pulmonary disease. J Thorac Dis. 2014; 6: S167-S72. doi:10.3978/j.issn.2072-1439.2014.03.07 jtd-06-S1-S167 [pii].

3. Barnes PJ. The cytokine network in chronic obstructive pulmonary disease. Am J Respir Cell Mol Biol. 2009; 41: 631-8. doi:10.1165/rcmb.2009-0220TR 2009-0220TR [pii].

4. Togo S, Liu X, Wang X, Sugiura H, Kamio K, Kawasaki S, et al. PDE4 inhibitors roflumilast and rolipram augment PGE2 inhibition of TGF-\{beta\}1-stimulated fibroblasts. Am J Physiol Lung Cell Mol Physiol. 2009; 296: L959-69. doi:10.1152/ajplung.00508.2007 00508.2007 [pii].

5. Grootendorst DC, Gauw SA, Verhoosel RM, Sterk PI, Hospers JJ Bredenbroker D, et al. Reduction in sputum neutrophil and eosinophil numbers by the PDE4 inhibitor roflumilast in patients with COPD. Thorax. 2007; 62: 1081-7. doi:thx.2006.075937 [pii] 10.1136/thx.2006.075937.

6. Calverley PM, Rabe KF, Goehring UM, Kristiansen S, Fabbri LM, Martinez FJ. Roflumilast in symptomatic chronic obstructive pulmonary disease: two randomised clinical trials. Lancet. 2009; 374: 685-94. doi:10.1016/S0140-6736(09)61255-1 S0140-6736(09)61255-1 [pii].

7. Hermann R, Nassr N, Lahu G, Peterfai E, Knoerzer D, Herzog R, et al. Steady-state pharmacokinetics of roflumilast and roflumilast $\mathrm{N}$-oxide in patients with mild and moderate liver cirrhosis. Clin Pharmacokinet. 2007; 46: 403-16. doi:4653 [pii] 10.2165/00003088-200746050-00003.

8. Hogg JC, Chu F, Utokaparch S, Woods R, Elliott WM, Buzatu L, et al. The nature of small-airway obstruction in chronic obstructive pulmonary disease. N Engl J Med. 2004; 350: 2645-53. doi:10.1056/NEJMoa032158 350/26/2645 [pii].

9. Gan WQ, Man SF, Senthilselvan A, Sin DD. Association between chronic obstructive pulmonary disease and systemic inflammation: a systematic review and a meta-analysis. Thorax. 2004; 59: 574-80.

10. Houslay MD, Schafer P, Zhang KY. Keynote review: phosphodiesterase-4 as a therapeutic target. Drug Discov Today. 2005; 10: 1503-19. doi:S1359-6446(05)03622-6 [pii] 10.1016/S1359-6446(05)03622-6.

11. Hatzelmann A, Morcillo EJ, Lungarella G, Adnot S, Sanjar S, Beume R, et al. The preclinical pharmacology of roflumilast--a selective, oral phosphodiesterase 4 inhibitor in development for chronic obstructive pulmonary disease. Pulm Pharmacol Ther. 2010; 23: 235-56. doi:10.1016/j.pupt.2010.03.011 S1094-5539(10)00045-3 [pii]. 